3 Hollander D, Vadheim CM, Brettholz E, Petersen G, Delahunty T, Rotter J. Increased intestinal permeability in patients with Crohn's disease and their relatives. Ann Intern Med 1986; 105: 883-5.

\section{Gall stones in Crohn's disease: another hypothesis}

EDITOR,-We read with interest the paper by Hutchinson et al (Gut 1994; 35: 94-7) suggesting that in Crohn's disease postoperative gall bladder hypomotility may be the main risk factor for the development of gall stones.

There are indeed several lines of evidence showing that decreased postprandial gall bladder motility participates in gall stone formation. ${ }^{1}$ Recent data, however, show that filling and emptying of the gall bladder are complex processes. The gall bladder cyclically contracts during fasting to up to $40 \%$ of its maximal volume, just before the occurrence of phase III of the migrating motor complex (MMC) in the antroduodenal area. ${ }^{2}{ }^{3}$ The mechanism of these cyclic contractions is not clear. Serum motilin peaks just before phase III of the MMC in the antroduodenal area. ${ }^{4}$ Moreover, exogenous motilin, producing premature MMCs in the gut, causes an increase in gall bladder motility similar to that seen during spontaneous gall bladder cyclic activity in dogs. ${ }^{35}$ It has therefore been suggested that the increment in plasma motilin concentrations may be responsible for the gall bladder contractions. ${ }^{5}$

We have recently studied 25 patients with uncomplicated, inactive Crohn's disease (mean Crohn's disease activity index 60.7). Gastrointestinal motility was studied during fasting ( 5 hours) and after a meal ( 1 hour) by standard perfusional manometry. ${ }^{6}$ Data obtained were compared with those of 33 healthy controls. The incidence of phase III of MMC was considerably reduced. In 13 of 25 patients phase III was absent ( $v 0$ of 33 of healthy controls $\mathrm{p}<0.001)$. In the other patients phase III was less frequent (one of 140 minutes $v$ one of 99 minutes, $\mathrm{p}<0.05)$, shorter in duration (4.6 (1) minutes $v 6.9$ (1), $\mathrm{p}<0.05)$, and rarely starting from the stomach (four of $25 v 18$ of $33, \mathrm{p}<0.01$ ). Mean motilin values were in the normal range, but lacked a clear peaking during phase III of the MMC.

The high prevalence of gall stones in Crohn's disease is well established. The accepted mechanism of disturbed enterohepatic circulation of bile salts in these patients could perhaps be enhanced if a change in gall bladder motility also occurs. Hutchinson et al suggest that gall bladder sludge may occur because of prolonged fasting or parenteral nutrition in the postoperative period. They found a higher incidence of gall stones in patients with previous laparotomy compared with patients who had not had any abdominal surgery (32\% v 13\%, $\mathrm{p}<0.005)$. They did not take into account, however, that the age of the patients, duration of the disease, and number of operations are dependent variables. The incidence of gall stones increases with age in Crohn's disease patients; but the incidence of surgery also increases in these patients with the duration of the disease.

We hypothesise that in some patients with Crohn's disease a reduction of cyclic phasic contractions of gall bladder occurs because of a decreased incidence of phases III of the
MMC in the antroduodenal area. The lack of periodic stirring and agitation of gall bladder bile may lead to supersaturation of bile and increase propensity for precipitation of salts and formation of gall stones in these patients. ${ }^{7}$

$\checkmark$ ANNESE

Division of Gastroenterology (CSS) Hospital IRCCS San Giovanni Rotondo, Italy G VANTRAPPEN Department of Gastroenterology, University Hospital Gasthuisberg, Leuven, Belgium

1 Grace PA, Poston GJ, Williamson RCN. Biliary motility. Gut 1990; 31: 571-82.

2 Toouli J, Bushell M, Stevenson G, Dent J, Wycherley A, Iannos J. Gallbladder emptying is relative to fasting duodenal migrating motor contractions. Aust NZ Ұ Surg 1986; 56: 147-51.

3 Matsumoto T, Sarna SK, Condon RE, Dodds WJ, Mochinaga N. Canine gall bladder cyclic motor activity. Am $\mathcal{F}$ Physiol 1988; 255: G409-16.

4 Vantrappen G, Peeters TL. Motilin. In: Handbook of physiology. Section 6. Vol II. Bethesda, MD:
American Physiology Society, 1989: 545-58.

5 Takahaski I, Suzuki T, Aizawa I, Itoh Z. Comparison of gallbladder contractions induced by motilin and CCK in dogs. Gastroenterology 1982; 82: 419-24.

6 Annese V, Bassotti G, Napolitano G, Betti C, Perri F, Usai P, et al. Most patients with inactive Crohn's disease have gastrointestinal motility disorders. Gastroenterology 1993; 104(4): A470-1

7 Ura K, Sarna SK, Condon RE. Antral control of gallbladder cyclic motor activity in fasting state. Gastroenterology 1992; 102: 470A-302.

\section{Reply}

Annese and Vantrappen state that the incidence of gall stones increases with age and duration of Crohn's disease. Our paper supports these statements (Gut 1994; 35: 94-7). The multivariate analysis of our data, however, showed that previous laparotomy also predisposed to gall stones, and that this was an important risk factor independent of age and duration of disease. Furthermore, the prevalence of gall stones was positively correlated with the number of previous operations. We found that the site of disease or intestinal resection did not seem to influence the risk of gall stones. These findings called into question the accepted explanation that changes in the enterohepatic circulation of bile salts predispose to gall stones in patients with Crohn's disease. Rather, we postulated that laparotomy may predispose to gall stones by inducing gall bladder hypomotility, and that the risk of gall stone formation increases with number of operations.

We did not study the mechanism of this phenomenon in our epidemiological study, but the interesting findings by Annese and Vantrappen on the migrating motor complex and motilin concentrations in patients with Crohn's disease may provide clues to the mechanism of gall bladder hypomotility in Crohn's disease.

R HUTCHNSON
The Queen Elizabeth Hospital,
Edgbaston,
Birmingham B15 2TH

Value of granulocyte scintigraphy in inflammatory bowel disease

EDITOR,-We read with great interest the article by Sciarretta et al (Gut 1993; 34: 1364-9) on the value of technetium-99m labelled granulocyte scintigraphy in Crohn's disease. Although we agree that technetium labelled granulocyte scintigraphy is of great value in the assessment of inflammatory activity in patients with inflammatory bowe disease (IBD), in providing information on the localisation, the extent, and the severity of the inflammation, we have some reservation concerning certain aspects of this study. The differentiation between ileal and ascending colon localisation is difficult. In a prospective study, ${ }^{1}$ granulocyte scintigraphy was compared with operative and endoscopic findings. This study shows the unsuccessful anatomical differentiation with granulocyte scintigraphy in five of eight patients with a hot spot in the right lower abdomen. Therefore, we are curious to discover the criteria of the authors to differentiate between both of the localisations when there is a hot spot in the right lower abdomen.

We are surprised by the finding of a $100 \%$ sensitivity and specificity in the detection of intestinal fistula and abscesses. To our knowledge, this is the first study to claim a $100 \%$ accuracy with these diagnoses. From Figs 1 and 2 in the article, we cannot distinguish abscess or fistula from simple skipped lesions, which are quite common in Crohn's disease. Which criteria have the authors used in differentiating between skipped lesions and fistula? From the article it is not clear how many patients received the 24 hour scintigram, which was their main criterion for diagnosing an abscess. With which techniques have the abscesses and fistulas been subsequently confirmed? Is it possible that the choice of techniques, or procedures to confirm the diagnoses, have influenced the $100 \%$ specificity finding? Furthermore, because not all of the patients have been checked for fistulas and abscesses (only those with evidence on granulocyte scintigraphy) the sensitivity might be lower than the $100 \%$ mentioned in the article. In our prospective, blinded study, the detection of abscesses and fistula with granulocyte scintigraphy was disappointing The sensitivity and specificity for abscesse was $60 \%$ and $78 \%$, and for fistulas $40 \%$ and $78 \%$, respectively. For detection of fistulas and abscesses in the acute phase, computed tomography was more accurate in this and other studies. ${ }^{1-4}$ Although the study by Sciarretta et al has confirmed the value of $99 \mathrm{~m}$ Tc-HMPAO granulocyte scintigraphy in assessment of activity and extent of IBD, the diagnostic accuracy of granulocyte scintigraphy might be less accurate than suggested. Therefore, despite the finding of Sciarretta et al, we would advise clinicians who see a patient with suspected abscess or fistula, to perform computed tomography before start ing corticosteroid treatment.

$$
\begin{array}{r}
\text { J J KOLKMAN } \\
\text { JC ROSS } \\
\text { Th H M FALKE } \\
\text { A S PEÑA } \\
\text { and Radiology, } \\
\text { Free University Hospital, } \\
\text { De Boelelaan 1117, } \\
1081 \text { HV Amsterdam, } \\
\text { The Netherlands }
\end{array}
$$

Departments of Gastroenterology, Nuclear Medicine
and Radiology,

1 Kolkman J, van Dijk DH, Bannink I, den Hollander W, Roos JC, Cuesta MCA, et al. CTScan and granulocyte scintigraphy enable assessment of localisation and inflammatory activity in IBD exacerbations. Gastroenterology 1994; 106: A713.

2 Silverman PM, Kelvin FM, Baker ME, Cooper C. Computed tomography of the ileocecal region. Comput Med Imaging Graph 1988; 12: 293-303. 
3 Greenstein OS, Rubesin SE, Jones B, Fishman EK, Bayless TM, Siegelman SS. Computed tomography vs barium studies in the acutely
symptomatic patients with Crohn's disease. $\mathcal{F}$ symptomatic patients with Crohn's disea
Comput Assist Tomogr 1987; 11: 10-09-16.

4 Gore RM, Cohen MI, Vogelzang RL, Neiman HL Tsang TK. Value of computed tomography in the detection of complications of Crohn's disease. Dig Dis Sci 1985; 30: 701-9.

\section{Reply}

EDITOR,-We thank Dr Kolkman et al for their letter about our paper on the clinical relevance of technetium- $99 \mathrm{~m}$ labelled granulocyte scintigraphy in Crohn's disease (Gut 1993; 34: 1364-9), not only for their positive considerations but also for the criticisms that give us the opportunity to clarify them.

Firstly, the problem of differentiation between ileum and ascending colon in the case of a hot spot in the right iliac fossa. In difficult cases, the scintigraphic study is done for 24 hours so the whole colon is visualised by labelled granulocytes eliminated in the lumen and so correctly attributes the scan image to the ileum or the colon.

The main point concerns Crohn's disease complications, abscesses and fistulas. In our work not all patients have been checked, so the term 'accuracy' is not statistically correct. But the systematic research of abscesses was not a goal of the study and so we started from the clinical suggestion of complication to perform computed tomography. In this subgroup of patients a positive scan for abscess or fistula had a $100 \%$ accuracy.

Scintigraphic differentiation between abscess and fistula is made on serial images, to see anomalous stabs between intestina loops or between intestine and adjacent tissues. The 24 hour scan was necessary in 45 patients. The examinations to confirm the complications (see the text) were performed in patients with clinical suggestions of the complications and not only in cases with a positive scan. We agree that computed tomography is more accurate for the screening of abscesses: in the methods section we say: 'when abscess or fistula complications were suspected, the final diagnosis was based on computed tomography ...', and this sentence is quite similar to the conclusion in Dr Kolkman's letter.

G SCIARRETTA A FURNO
Department of Gastroenterology and Nuclear
Medicine,

\section{Benign intracranial hypertension}

EDITOR,-We read with interest the report of two patients who developed so called benign intracranial hypertension (BIH) during episodes of inflammatory bowel disease (IBD) treated with corticosteroids, but would argue that the corticosteroids were probably not to blame (Gut 1994; 35: 423-5). It is increasingly realised that $\mathrm{BIH}$ is a syndrome rather than a specific diagnosis, and that the most common identifiable underlying cause is cerebral venous thrombosis. This may affect either the major dural venous sinuses or the superficial cortical veins, and can present with either the syndrome of BIH or focal deficit resulting from venous infarction. There is well recognised association between IBD and cerebral venous thrombosis. ${ }^{1-5}$ This probably reflects a general tendency to thrombosis in IBD rather than the effects of treatment: certainly cases have been reported where corticosteroids were not prescribed ${ }^{1-3}$ or had been completely withdrawn (as described by Jackson et $a l^{5}$ and the authors in a paper recently submitted for publication).

Indeed it must be asked whether there really is a genuine association between BIH and corticosteroid treatment. Many of the other diseases that are treated with corticosteroids are also themselves thrombophilic. An example would be the recent report of BIH in a patient with corticosteroid treated nephrotic syndrome, where the BIH resolved with anticoagulation. 6

The diagnosis of cerebral venous thrombosis is not excluded by a normal brain scan with computed tomography; this requires either magnetic resonance brain scanning with special angiography sequences or conventional cerebral angiography. Our policy is to pursue these detailed investigations in patients where the syndrome of $\mathrm{BIH}$ is accompanied by a thrombophilic disorder, particularly as there is increasing evidence that anticoagulation may be a useful treatment. ${ }^{7}$ P J TOGHILI

Department of Medicin T JASPAN

Department of Neuroradiology G LENNOX

Department of Neurolog Department of Neurology
Queen's Medical Centre, University Hospital, Nottingham NG7 $2 U H$

1 Averback P. Primary cerebral venous thrombosis in adults: the diverse manifestations of an underrecognised disease. Ann Neurol 1978; 3 81-6.

2 Schneiderman JH, Sharpe JA, Suffon DMC Cerebral and retinal vascular complications of inflammatory bowel disease. Ann Neurol 1979, 5: 331-7.

3 Yerby MS, Bailey GM. Superior sagittal sinus thrombosis ten years after surgery for ulcerative colitis. Stroke 1980; 11: 294-6.

4 Johns DR. Cerebrovascular complications of inflammatory bowel disease. Am $\mathcal{F}$ Gastroenterol 1991; 86: 367-70.

5 Jackson M, Lennox G, Jaspan T, Jefferson D. Cerebral venous and systemic thrombosis in Cerebral venous and systemic thrombosis in ulcerative

6 Sakamaki Y, Nakamura R, Uchida M, Saito T, Okajima S. A case of pseudotumour cerebri following glucocorticoid therapy in which warfarin prevented recurrence. $\not p n ~ \mathcal{F}$ Med 1990; 29: 566-70.

7 Einhaupl JM, Villringer A, Meister W. Heparin treatment in sinus venous thrombosis. Lancet 1991; 338: 597-600.

\section{- \\ BOOK REVIEWS}

An Illustrated Guide to Gastrointestinal Motility. Edited by D Kumar, D Wingate. Second edition. (Pp 700; illustrated $£ 125.00$.) Edinburgh: Churchill Livingstone, 1993.

The implication of abnormal gastrointestinal motility in the pathogenesis of common disorders and symptoms has been well established over the past 20 years but the details of measurement and the interpretation of motility traces remain obscure to all but a few directly involved in the field. While clinicians are often confused about science, non-clinical physiologists may be unaware of the clinical problems that need to be solved.

This book aims to provide 'a concise, practical and fully illustrated account by acknowledged experts of, not only the motor physiology and pathophysiology of the gut, but also methods by which it may be studied'. In this, it most definitely succeeds and, although, with over 700 pages, 'concise' may not be the best description, it is divided up into sections and short chapters, which makes it very readable and easy for reference. Since the first edition, new sections have been added to deal with systems that regulate and modulate gastrointestinal motility and many of the other chapters have been rewritten. Certainly, the editors have collected a very impressive array of internationally acclaimed authors in the field, from different countries and different disciplines. The middle section deals with methods of measuring motility from perfused tube manometry through electrogastrography to computerised wave form analysis. The techniques are described in considerable detail, making it possible to use the book for practical problems of everyday clinical measurement and throughout the book the authors are appropriately critical and not afraid to discuss the problems of measurement and interpretation in this field.

Each chapter is extensively referenced, which is particularly valuable for researchers who wish to read more widely and look up the original sources; and the whole book is extensively illustrated - so well, in fact, that sometimes the text is almost lost! (for example, between pages 105-107 and 109-111). The 40 chapters are divided into seven sections and the excellent index makes reference to the same subject in different chapters easy. The wealth of illustration is reflected in the price.

Although it is always possible for a reviewer to find small details with which they disagree, this book is a mine of information and should be available for reference to all those involved in gastroenterology or in laboratory testing and measurement of motility.

A G JOHNSON

Small Bowel Transplantation. By D R Grant, R F M Wood. (Pp 142; illustrated; £60.00.) London: Edward Arnold, 1994.

The comparative success of parenteral nutrition in the treatment of patients with intestinal failure and the disappointing early results of small bowel transplantation relegated this topic to the backwaters of the transplant world. This is now changing and small bowel transplantation should become an established form of treatment for intestinal failure in the near future. There are many problems still to be resolved, but the progress of research and clinical practice has been comprehensively summarised in this well produced publication.

The book reviews the causes and current treatment options of small bowel failure, experimental animal models used to study small bowel transplantation, the problems of acute and chronic rejection, organ preservation, and the physiology and function of the gut, with particular reference to mucosal defence and bacterial translocation. There is an extensive clinical review of current results 